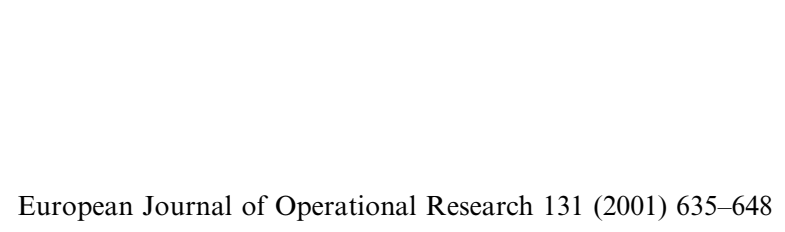

\title{
Sourcing decisions with capacity reservation contracts
}

\author{
Dogan A. Serel ${ }^{\mathrm{a}, *}$, Maqbool Dada ${ }^{\mathrm{b}}$, Herbert Moskowitz ${ }^{\mathrm{b}}$ \\ ${ }^{a}$ Faculty of Business Administration, Bilkent University, 06533 Bilkent, Ankara, Turkey \\ ${ }^{\mathrm{b}}$ Krannert Graduate School of Management, Purdue University, West Lafayette, IN 47907, USA
}

Received 7 July 1998; accepted 20 March 2000

\begin{abstract}
By committing to long-term supply contracts, buyers seek to lower their purchasing costs, and have products delivered without interruption. When a long-term contract is available, suppliers are less pressured to find new customers, and can afford to charge a price lower than the prevailing spot market price. We examine sourcing decisions of a firm in the presence of a capacity reservation contract that this firm makes with its long-term supplier in addition to the spot market alternative. This contract entails delivery of any desired portion of a reserved fixed capacity in exchange for a guaranteed payment by the buyer. We investigate rational actions of the two parties under two different types of periodic review inventory control policies used by the buyer: the two-number policy, and the base stock policy. When typical demand probability distributions are considered, inclusion of the spot market source in the buyer's procurement plan significantly reduces the capacity commitments from the long-term supplier. (c) 2001 Elsevier Science B.V. All rights reserved.
\end{abstract}

Keywords: Supply chain management; Long-term contracts; Inventory; Capacity reservation

\section{Introduction}

The procurement of raw materials and components used in the manufacturing process is a critical managerial task. In the US, cost of purchased inputs constitute about $50 \%$ of its total sales for a typical manufacturing firm (Subramaniam, 1998), implying that overlooking the

\footnotetext{
* Corresponding author. Tel.: +90-312-290-2415; fax: +90312-266-4958.

E-mail address: serel@bilkent.edu.tr (D.A. Serel).
}

cost of inputs may lead to considerable financial losses. In dealing with its suppliers, a company may decide to enter into short- or long-term contractual relations. Ongoing developments in the global economy have significantly influenced and altered the traditional form of manufacturer-supplier relationships. The adoption of just-in-time production and competitive pressures on quality have caused leading companies to start approaching their suppliers as long-term outside partners instead of adversarial parties. In this paper, we develop analytical models to examine the manufacturer-supplier relations from both parties' 


\begin{tabular}{|c|c|c|c|}
\hline & \multirow{2}{*}{$k$} & \multirow{2}{*}{$\begin{array}{l}\text { cut-off unit capacity price over which the } \\
\text { optimal base stock policy includes two } \\
\text { suppliers }\end{array}$} \\
\hline \multicolumn{2}{|c|}{ Notation } & & \\
\hline \multirow{2}{*}{$\begin{array}{l}B 2 \\
B 12\end{array}$} & $\begin{array}{l}2 \text { buyer's optimal expected profit per period } \\
\text { in the absence of Supplier } 1\end{array}$ & $\begin{array}{l}L(.) \\
p\end{array}$ & \multirow{3}{*}{$\begin{array}{l}\text { expected shortage-holding cost per period } \\
\text { unit selling price charged by the buyer } \\
\text { average delivery amount per period in the } \\
\text { standard single supplier problem with } \\
\text { optimal base stock level equal to } r\end{array}$} \\
\hline & $\begin{array}{l}\text { buyer's optimal expected profit per period } \\
\text { under base stock policy }\end{array}$ & $Q_{1}(r)$ & \\
\hline$c_{\mathrm{s}}$ & $\begin{array}{l}\text { unit production cost of Supplier } 1 \text { and } \\
\text { Supplier } 2\end{array}$ & $S 1$ & \\
\hline$c$ & unit capacity price charged by Supplier 1 & $S 2$ & \multirow{3}{*}{$\begin{array}{l}\text { Supplier 1's expected profit per period } \\
\text { Supplier 2's expected profit per period } \\
\text { combined expected profit per period of } \\
\text { the buyer, Supplier 1, and Supplier } 2 \\
\text { Supplier 1's expected profit per period } \\
\text { when the buyer implements a base stock } \\
\text { policy and uses only Supplier } 1\end{array}$} \\
\hline $\begin{array}{l}c_{2} \\
D\end{array}$ & $\begin{array}{l}\text { unit supply price charged by Supplier } 2 \\
\text { value of capacity reservation contract to }\end{array}$ & $T$ & \\
\hline$E P$ & $\begin{array}{l}\text { the buyer } \\
\text { buyer's expected profit per period under } \\
\text { base stock policy }\end{array}$ & $X_{1}$ & \\
\hline $\begin{array}{l}f(.) \\
F(.)\end{array}$ & $\begin{array}{l}\text { probability density function for demand } \\
\text { cumulative probability distribution func- } \\
\text { tion for demand }\end{array}$ & $X_{2}$ & \multirow{3}{*}{$\begin{array}{l}\text { Supplier l's expected profit per period } \\
\text { when the buyer implements a base stock } \\
\text { policy and uses both suppliers } \\
\text { random demand per period } \\
\text { mean demand } \\
\text { shortage penalty cost per unit }\end{array}$} \\
\hline$F_{\mathrm{c}}()$. & $\begin{array}{l}\text { complementary cumulative probability } \\
\text { distribution function for demand }\end{array}$ & $\begin{array}{l}Y \\
\mu\end{array}$ & \\
\hline $\begin{array}{l}h \\
J_{\max }\end{array}$ & $\begin{array}{l}\text { holding cost per unit } \\
\text { maximum expected joint profit of the } \\
\text { buyer and Supplier } 1\end{array}$ & $\pi$ & \\
\hline
\end{tabular}

perspectives, and explore the conditions influencing the choice of long- or short-term supply relationships.

Various factors influence the relationships between manufacturers and their suppliers. Supplier involvement in the product development process, cost and quality of delivered materials, and risks of supply disruptions are some major factors considered by manufacturers (De Toni and Nassimbeni, 1999). Helper and Sako (1995) survey recent trends in supplier relations in the US and Japanese automotive industries.

The reasons for the adoption of different procurement strategies by firms have been explored in the economics literature using the concept of "Transaction Costs" (Williamson, 1991). According to this viewpoint, a long-term relationship between a buyer and a supplier is more likely when the assets required by the relationship do not have alternative uses, i.e., when one party is highly dependent on the other. De Toni and Nassimbeni (1999) discuss comparative advantages of “arm's- length" sourcing (spot markets) and long-term partnerships. They also present a survey of Italian companies, which, in consistence with Transaction Costs theory, points out that manufacturers are more inclined (compared to arm's-length relationship) to enter long-term relationships with suppliers when an advanced operational link (e.g., deliveries synchronized with the production schedule) is established between the parties. Subramaniam (1998) discusses how corporate financing decisions can alter the buyer's motives for opportunistic behavior in its relations with its suppliers. The issue of supplier competition in procurement contracts has also been analyzed by using "bidding" models (Seshadri et al., 1991).

The management of material flows across a supply chain is an important part of the operations management field. The classical inventory theory prescribes optimal purchasing policies for the buyer by minimizing the sum of purchasing, holding, and shortage costs (Porteus, 1990). In recent years, there has been a growing interest in 
the analysis of supply contracts (Tsay et al., 1999). A number of papers discuss supply arrangements that allow the buyer to change, after its initial commitment, the quantity of goods purchased in the future, thus mitigating risks caused by demand uncertainty (Bassok and Anupindi, 1997). Supply contracts providing flexibility with regard to the timing of the purchase in an environment of deterministic demand and random purchase prices have been analyzed by $\mathrm{Li}$ and Kouvelis (1999). Cohen and Agrawal (1999) compare the desirability of a long-term contract with predetermined purchase price against that of a short-term contract subject to fluctuating market prices. These papers focus on the buyer's optimal action, and do not analyze the supplier perspective. As in Cohen and Agrawal (1999), we model that a buyer can choose from long or short term contracts. There is no price uncertainty in our model; but we consider the possibility of simultaneous use of both types of contracts, and look into the supplier's optimal behavior.

\section{A buyer-supplier equilibrium model}

We consider a manufacturer who buys an item as an input for its manufacturing process from sources outside the organization. Suppose the level of output of the manufacturing process is linearly related to the level of input, and the market demand for the output is uncertain. Without loss of generality, we assume one unit of input is required for one unit of output. We assume periodic review inventory control for the input, i.e., the buyer places purchase orders periodically, the order amounts depending on the current inventory level at the ordering instants. For ease of exposition, we assume that the input is immediately delivered from the supplier, and the time to transform the input to output is negligible compared to the period length, so the demand for the output of the manufacturing process per period can also be regarded as the demand for the input. Thus, the buyer (manufacturer) faces an inventory problem in which it needs to tradeoff the decreasing costs of holding less output items in stock with the higher costs of incurring shortages. We also assume unit sales price (revenue) $p$, unit holding cost $h$ per period, and unit shortage penalty cost $\pi$, charged at the end of the period. If the demand in a period exceeds the stock on hand, excess demand is lost.

The buyer's problem is to decide in each period how much input to order so as to maximize its expected profit. Although a variety of factors may be important in selecting a supplier, the most dominant factor in practice is usually the purchase cost (Li and Kouvelis, 1999). In this paper, we assume that the price charged by the supplier will be the primary determinant of buyer-supplier relationships. Further, in our model, in order to establish a long-term supply relation, the buyer demands the supplier to offer a supply price lower than that offered by other suppliers. In moving toward longer horizon supply contracts, reduction in supply cost is among the main benefits desired by the buyer (Lyons et al., 1990).

Regarding the input item, we assume there is a group of homogenous suppliers, each of which can supply the item at a constant unit price without any long-term commitment, i.e., they constitute the spot market alternative for the buyer. The buyer can enter a long-term supply relation with a preferred supplier provided it will reduce its costs. However, there should be a mechanism to compensate the supplier for its acceptance of supplying the item at a lower-than-market cost. To represent such a mechanism, we consider a supply arrangement that we refer to as a capacity reservation contract. In this arrangement, which is implemented by some US car manufacturers (Henig et al., 1997), the buyer guarantees a fixed payment to the supplier in return for the delivery of any desired portion of a reserved fixed capacity. If the realized demand in any period is low, less than capacity is ordered; however, if the observed demand is higher, and therefore there is not enough stock on hand, the entire capacity is ordered. Hence, the buyer essentially buys the right to order up to a certain number of units from the supplier each period. In practice, similar supply arrangements designed to provide the buyer with flexibility in the order quantity are observed in different industries including textile garment (Eppen and Iyer, 1997), and integrated circuit manufacturing (Brown and Lee, 1997). Barnes-Schuster et al. 
(1998) study two-period supply contracts involving options. Although we do not explicitly quantify the benefits of a capacity reservation contract for the supplier, the major benefits can be listed as the establishment of a long-term business relationship, reduced need to find new customers, and smoother future cash flows. Reserving capacity is also regarded as one of the counter-measures of the "bullwhip effect", i.e., it helps to reduce the variance of the orders issued to the supplier (Lee et al., 1997).

We assume that all suppliers (including the preferred supplier) incur the same unit production cost, $c_{\mathrm{s}}$ for the item in consideration, and the spot market price charged to buyer is $c_{2}$ per unit. The buyer has to decide how much capacity to reserve from the preferred supplier given the cost of this reservation. The preferred supplier has to charge a suitable price for the capacity reservation contract, knowing the availability of the spot market alternative for the buyer. Thus, the market price charged by the group of short-term suppliers leads to an equilibrium in which the buyer and the preferred supplier make their optimal decisions to maximize their expected profits. We assume that the cost of reserved capacity is proportional to the reservation amount. Each period, the buyer pays the long-term supplier a fixed amount of $c R$. In exchange for this fee, the supplier agrees to provide up to $R$ units of product each period. Thus, $c$ is the unit capacity price specified by the supplier. The unused capacity cannot be sold to a third party, and has no value to the supplier or the buyer.

Finally, we assume that demands during each of the periods are i.i.d. random variables, denoted by $Y$, and that, as commonly assumed in the supply contracts literature, the information about the demand distribution and the buyer's cost parameters is fully available to the long-term supplier.

\section{Optimal decisions}

\subsection{Buyer's problem}

The buyer's problem is structurally very similar to the inventory problem embedded in a transportation contract, and studied by Henig et al.
(1997). As we have two different supply options for the buyer, shipments in their transportation contract occur in two ways: the prespecified truck volume, and emergency shipments at extra cost. The stochastic dynamic programming problem faced by the buyer can be solved in two steps. First, we ignore the contract costs by assuming $c=0$, and determine the optimal inventory control policy for a given $R$. In the second step, we include the contract cost $c R$ in the expected profit function and determine the optimal value of $R$. Henig et al. (1997) have shown that under the total expected discounted cost criterion and backordered demand assumption, the optimal inventory control policy for a given $R$ has two critical numbers, $S L$ and $S U$. Let $I$ be the inventory level before ordering, and $Z$ be the inventory level after ordering at the beginning of a period. Henceforth, we refer to the preferred supplier as Supplier 1, and the spot market sources as Supplier 2. Let $q_{1}$ be the amount ordered from Supplier 1. Then the optimal policy requires that:

$$
\begin{array}{lll}
Z=I & \left(q_{1}=0\right) & \text { if } S U \leqslant I, \\
Z=S U & \left(q_{1}=S U-I\right) & \text { if } S U-R \leqslant I \leqslant S U, \\
Z=I+R & \left(q_{1}=R\right) & \text { if } S L-R \leqslant I \leqslant S U-R, \\
Z=S L & \left(q_{1}=R\right) & \text { if } I \leqslant S L-R .
\end{array}
$$

Henig et al. (1997) have conjectured that (SL, SU) type policy will continue to be optimal under the long run average cost criterion. Since it is difficult to find the values of $S L$ and $S U$ analytically, we utilize numerical methods. After finding the steady state probabilities of the inventory levels based on a discrete Markov chain, we can conduct a numerical search for $S L$ and $S U$ (Henig et al., 1997).

\subsection{Supplier's problem}

The unit capacity price $c$ is determined as a result of negotiations between the buyer and Supplier 1. Supplier 1 needs to take into account the fact that as $c$ increases, the buyer will reduce the volume of business with him. Since Supplier 1 has complete knowledge of the buyer's problem, he correctly assesses the average amount of orders to 
be received from the buyer if the buyer makes the optimal ordering decision to maximize his expected profit. Supplier 1 can use this information to determine the optimal value of $c, c^{*}$, that will maximize expected profit given the buyer's and Supplier 2 's cost parameters. Thus, it can be thought that the writing of the contract is done in two stages. In the first stage, Supplier 1, anticipating the buyer's action, quotes the unit capacity price $c$. In the second stage, the buyer, given $c$, decides how much to order from Supplier 1. In game theoretic terminology, the buyer and Supplier 1 play a Stackelberg game (Gibbons, 1992, p. 61).

In order to determine the optimal capacity price to charge the buyer, Supplier 1 needs to compute the average amount it will supply each period for all possible values of reserved capacity. This will usually involve substantial computational work.

Because the two-number control policy studied by Henig et al. (1997) requires numerical techniques for finding the optimal solution, it is difficult to understand the underlying structural relationships between the parameters of the problem. This is especially the case when the problem is studied from the supplier's perspective. To facilitate obtaining structural results, in this paper, we use a base stock policy as an approximate model to study the tradeoffs involved in a capacity reservation environment. Our computational results indicate that total expected profit of all parties in the system (buyer, Supplier 1, and Supplier 2) remains fairly stable under different inventory control policies used by the buyer. From a broader angle of view, the total expected profit in the system can be regarded as the overall societal gain, which is found to be quite robust to the choice of inventory control policy. Moreover, the base stock type inventory control policy is a reasonable choice from a practical standpoint; it is well-known and widely used by inventory management practitioners.

\section{Base stock policy}

\subsection{Maximizing buyer's expected profit}

According to a stationary base stock (orderup-to) control policy, at the beginning of each period, additional stock is ordered to bring the inventory level to the base stock level, $S$. Let $F(y), F_{\mathrm{c}}(y)$ and $f(y)$ be the cumulative distribution function (cdf), complementary cdf and probability density function of $Y$, respectively. The assumptions of stationary base stock policy and immediate order delivery imply that the average holding and shortage costs per period, $L(S)$, is

$$
\begin{aligned}
L(S)= & h \int_{0}^{S}(S-y) f(y) \mathrm{d} y \\
& +\pi \int_{S}^{\infty}(y-S) f(y) \mathrm{d} y .
\end{aligned}
$$

As long as the planning horizon is sufficiently long, the effect of the inventory on hand at the beginning of the first period on the optimal profit per period can be neglected. Alternatively, it may be assumed that the cost of bringing the initial inventory on hand to $S$ is treated as a sunk cost. Let $Q_{i}$ be the average order quantity per period from supplier $i, i=1,2$. The starting inventory level does not change from one period to another so that we can compute $Q_{i}$ as

$$
\begin{aligned}
Q_{1}(R)= & \int_{0}^{R} y f(y) \mathrm{d} y+R \int_{R}^{\infty} f(y) \mathrm{d} y, \\
Q_{2}(R, S)= & \int_{R}^{S}(y-R) f(y) \mathrm{d} y+(S-R) \\
& \times \int_{S}^{\infty} f(y) \mathrm{d} y .
\end{aligned}
$$

The optimal value of $R$ will always be less than or equal to the optimal value of $S$, since if $R$ exceeds $S$, the $(R-S)$ portion of the reserved capacity can never be used. If the optimal $R$ is equal to the optimal $S$, it indicates that Supplier 2 will never be used. If $R<S$ in the optimal solution, the buyer uses both suppliers. Denoting the expected profit per period by $E P$, the buyer's optimization problem is

$$
\begin{aligned}
\max & E P(R, S)= \\
\text { subject to } & 0 \leqslant R \leqslant S .
\end{aligned}
$$


Using Eqs. (1)-(4) and Leibniz's rule (Nahmias, 1993, p. 291),

$$
\begin{gathered}
\partial E P / \partial S=\left(c_{2}-p-\pi-h\right) F(S)+p+\pi-c_{2}, \\
\partial E P / \partial R=c_{2} F_{\mathrm{c}}(R)-c .
\end{gathered}
$$

Recall that $F_{\mathrm{c}}(R)=1-F(R)$. Since $E P$ can be shown to be jointly concave on $S$ and $R$, and the constraint function is linear, Karush-KuhnTucker (KKT) optimality conditions (Bazaraa et al., 1993) can be used to determine the optimal solution to the problem. Let $\lambda$ and $v$ be the Lagrange multipliers. The KKT conditions are:

$$
\begin{gathered}
\partial E P / \partial R=\lambda-v, \quad \partial E P / \partial S=-\lambda, \\
\lambda(R-S)=0, \quad v R=0, \quad \lambda, v \geqslant 0 .
\end{gathered}
$$

The first-order conditions give:

$$
\begin{aligned}
& F\left(S^{*}\right)=\left(p+\pi-c_{2}\right) /\left(p+\pi+h-c_{2}\right), \\
& F\left(R^{*}\right)=\left(c_{2}-c\right) / c_{2} .
\end{aligned}
$$

$S^{*}$ and $R^{*}$ maximize the buyer's expected profit if they satisfy $S^{*}>R^{*}$. If $R^{*} \geqslant S^{*}$, the constraint (4) is binding and the optimal solution needs to satisfy $R=S$. Let $R^{* *}=S^{* *}$ be the optimal pair for the binding constraint case. The KKT conditions imply that $R^{* *}$ and $S^{* *}$ satisfy

$\partial E P / \partial S+\partial E P / \partial R=0$.

Solving (7) after substituting $R=S$, we obtain

$F\left(S^{* *}\right)=(p+\pi-c) /(p+\pi+h)$.

Thus, the optimal order-up-to level and reserved capacity can be determined easily after checking whether $S^{*}>R^{*}$. From the monotonicity of $F(y)$, $R^{*}<S^{*}$ implies that

$c>k \equiv h c_{2} /\left(p+\pi+h-c_{2}\right)$.

If $c$ is less than $k$, Supplier 1 will be the exclusive supplier for the buyer. Note that the threshold price, $k$, does not depend on the demand distribution characteristics.

The optimal values of decision variables that maximize the buyer's expected profit are summarized in Table 1. We note that although we have assumed there is no extra variable cost (i.e.,
Table 1

Summary of optimal base stock policy for the buyer

\begin{tabular}{ll}
\hline Case & Optimal policy \\
\hline$c \leqslant k$ & Order from Supplier 1 only, $S=R=S^{* *}$ \\
$k<c<c_{2}$ & Order from both, $S=S^{*}, R=R^{*}$ \\
$c \geqslant c_{2}$ & Order from Supplier 2 only, \\
& $R=0, S=S^{*}$ \\
\hline
\end{tabular}

proportional to order volume) for the purchases from Supplier 1, the preceding analysis can also be easily extended to the cases where such costs exist.

\subsection{Value of the capacity reservation contract to the buyer}

We now determine the expected benefit to the buyer of implementing a capacity reservation contract. For the sake of brevity, we consider only the case when $k<c<c_{2}$. We use $B 12$ to represent the buyer's maximal expected total profit when a capacity reservation agreement with Supplier 1 as well as the market source Supplier 2 are available to the buyer. $B 2$ represents the buyer's maximal expected total profit in the absence of Supplier 1. The difference between $B 12$ and $B 2$ can be regarded as the value of the capacity reservation contract to the buyer after adjusting for market conditions.

$$
\begin{aligned}
& B 2=E P\left(0, S^{*}\right)=\left(p-c_{2}\right) Q_{1}\left(S^{*}\right)-L\left(S^{*}\right), \\
& B 12=E P\left(R^{*}, S^{*}\right)=p Q_{1}\left(R^{*}\right)-c R^{*} \\
& +\left(p-c_{2}\right)\left[Q_{1}\left(S^{*}\right)-Q_{1}\left(R^{*}\right)\right]-L\left(S^{*}\right) .
\end{aligned}
$$

Let $D$ be the difference between $B 12$ and $B 2$. As described above, $D$ denotes the expected savings for the buyer made possible by entering a capacity reservation agreement with Supplier 1. After some algebra and using (2) and (6), we obtain

$D=B 12-B 2=c_{2} \int_{0}^{R^{*}} y f(y) \mathrm{d} y$.

Thus, the value of $D$ is determined by $c_{2}, c$, and the demand distribution. 
Although it is always possible to compute $D$ numerically, analytical expressions can be obtained easily for many families of demand distributions. For further insight, we use a meanpreserving transformation to compare the expected savings, $D$, across demand distributions with identical mean values and different uncertainty levels (Gerchak and Mossman, 1992). The following proposition describes the relationship between the variability of the demand distribution and the expected savings from the capacity reservation contract.

Proposition 1. The value of the capacity reservation contract under a base stock policy is inversely related to the level of uncertainty in demand.

\section{Proof. See Appendix A.}

A high variability in the demand for the manufacturer's output also implies high variability in the input item demand. The higher demand uncertainty will lead to a lower utilization of the reserved capacity, which increases the effective supply cost for the buyer. Thus, as the demand variation increases, the capacity reservation contract becomes less appealing to the buyer. Even though suppliers may be able to pool demands from different buyers, nevertheless, in a competitive supplier market, the capacity reservation contract will be more attractive for a supplier as the sales uncertainty increases. Correspondingly, to a large extent, the existence of this kind of contracts in highly volatile market environments such as semiconductors can be attributed to the desires of suppliers to ensure the continuity of sales.

\subsection{Maximizing supplier's expected profit}

Equipped with the information given in Table 1, Supplier 1 needs to evaluate two different profit functions, $X_{1}$ and $X_{2}$, which describe its expected profit as $c$ varies from 0 to $k$, and from $k$ to $c_{2}$, respectively. $X_{1}$ and $X_{2}$ refer to Supplier 1's expected profit when the buyer, by following the optimal policy given in Table 1, orders from only Supplier 1, and from both suppliers, respectively.

This yields the following two optimization problems:

(I) $\underset{c}{\operatorname{Maximize}} X_{1}=c R^{* *}-c_{\mathrm{s}} Q_{1}\left(R^{* *}\right)$

subject to $c \leqslant k$,

$$
F\left(R^{* *}\right)=(p+\pi-c) /(p+\pi+h) .
$$

(II) $\underset{c}{\operatorname{Maximize}} X_{2}=c R^{*}-c_{\mathrm{s}} Q_{1}\left(R^{*}\right)$

subject to $k<c<c_{2}$,

$$
F\left(R^{*}\right)=\left(c_{2}-c\right) / c_{2} \text {. }
$$

Clearly, the maximum possible expected profit of Supplier 1 is given by the constrained maximum of $X_{1}$ and $X_{2}$. The feasible regions and objective functions in these two formulations take into account the buyer's optimal ordering policy given that $c$ lies between 0 and $c_{2}$.

It is relatively easy to determine the maximum expected profit of Supplier $1, X^{*}$, if $X_{1}$ and $X_{2}$ are concave functions of $c$. When we have this concavity property, $X^{*}$ will occur at one of the following three points: the unique unconstrained maximum of $X_{1}$ or $X_{2}$, or sometimes at the intersection point of $X_{1}$ and $X_{2}$ which corresponds to the case $c^{*}=k$.

Let $w_{i}$ be the value of $c$ that sets the first derivative of $X_{i}$ with respect to $c$ to zero, $i=1,2$. Also let $X_{i}(w)$ be the value of $X_{i}$ evaluated at $c=w$. If both $X_{1}$ and $X_{2}$ are concave functions of $c, X^{*}$ is given by Table 2 .

The following proposition states that $X_{1}$ and $X_{2}$ are concave if the demand distribution belongs to the large class of increasing failure rate (IFR) distributions. For example, the normal distribution, which frequently appears in the inventory literature, is IFR.

Table 2

Optimal expected profit of Supplier 1 under a base stock policy

\begin{tabular}{ll}
\hline Case & $X^{*}$ \\
\hline$w_{1} \leqslant k, w_{2}<k$ & $\max \left\{X_{1}\left(w_{1}\right), X_{2}(k)\right\}=X_{1}\left(w_{1}\right)$ \\
$w_{1} \leqslant k, w_{2} \geqslant k$ & $\max \left\{X_{1}\left(w_{1}\right), X_{2}\left(w_{2}\right)\right\}$ \\
$w_{1}>k, w_{2}<k$ & $X_{1}(k)=X_{2}(k)$ \\
$w_{1}>k, w_{2} \geqslant k$ & $\max \left\{X_{1}(k), X_{2}\left(w_{2}\right)\right\}=X_{2}\left(w_{2}\right)$ \\
\hline
\end{tabular}


Proposition 2. If the demand distribution is IFR, both $X_{1}$ and $X_{2}$ are concave on $c$.

\section{Proof. See Appendix A.}

As an example, in Appendix A, we present explicit expressions for finding the values of $w_{1}$ and $w_{2}$ for the Weibull distribution which is an attractive distribution for modeling purposes since, by appropriate choice of its distribution parameters, it can also closely approximate several other unimodal distributions such as the normal and lognormal. Clearly, by using Table 2, it is also possible to derive the optimal $c$ values for other analytically tractable demand distributions. If the analytical treatment is impracticable, numerical methods can be easily used to find an optimal solution, since the search is limited to one variable.

\section{Buyer-supplier coordination}

First note that, within the boundaries of our model, in order for a capacity reservation contract to exist, Supplier 1 and Supplier 2 should exist as separate entities. If the same supplier were to offer both the capacity reservation contract and the spot market contract with supply price $c_{2}$ simultaneously, in order to maximize his expected profit, the optimal decision for this supplier would be to act as an open market supplier, whether the buyer uses a base stock or an $(S L, S U)$ policy. Note that it is a different issue whether the optimal per-unit price for this supplier continues to be $c_{2}$ if he is allowed to freely choose a per-unit price.

Coordinating the actions of a buyer and a supplier so as to improve the overall system profits has been studied by various researchers (Thomas and Griffin, 1996). Now we consider the system consisting of Supplier 1 and the buyer. The maximum system profit is obtained when the buyer and Supplier 1 are vertically integrated. In this case, the buyer will not use Supplier 2 and the optimal policy will be a base stock policy with base stock level, $S$, given by

$F(S)=\left(p+\pi-c_{\mathrm{s}}\right) /\left(p+\pi+h-c_{\mathrm{s}}\right)$.
Clearly, the optimal capacity volume will be equal to $S$. The maximum expected system profit, $J_{\max }$, is

$J_{\max }=\left(p-c_{\mathrm{s}}\right) Q_{1}(S)-L(S)$.

The buyer-supplier coordination is often difficult to achieve in practice (Maloni and Benton, 1997). A great majority of manufacturers depend on outside suppliers, and do not vertically integrate (Subramaniam, 1998).

\section{Numerical examples}

A set of numerical examples are presented in this section to illustrate the expected distribution of system profits among the parties under various circumstances. The results for the base stock, $(S L$, $S U$ ), and buyer-Supplier 1 coordination policies are displayed separately. We assume that demand is distributed as Weibull with mean $\mu=30$, and excess demand is lost. We also specify the values of $c_{2}, c_{\mathrm{s}}, h$, and $\pi$. We then calculate the expected profits of the buyer, Supplier 1, and Supplier 2 for selected $c$ values under several combinations of $p$ and $\alpha$ values. Let $S 1$ and $S 2$ denote the expected profits of Supplier 1 and Supplier 2, respectively. Supplier 2's expected profit per period is

$S 2=\left(c_{2}-c_{\mathrm{s}}\right) Q_{2}$.

$B$ refers to the buyer's optimal expected profit. Also let $T$ denote the sum of the expected profits of all three parties in the system.

\subsection{Base stock policy results}

Since we keep the average demand constant, the demand distribution becomes less variable as $\alpha$ increases; the case $\alpha=1$ corresponds to the exponential distribution. The results in Table 3 show that the buyer's expected profit increases as $\alpha$ increases, which can be explained by the decrease in the demand variability. Analogously to Proposition 1 , the value of the capacity reservation contract to the buyer (at $c=5$ ) increases as $\alpha$ increases; e.g., in Case $1, D=46(=214.2-168.2)$ for $\alpha=1$, whereas $D=87.3$ for $\alpha=2$. 
Table 3

Expected profits under base stock policy

\begin{tabular}{|c|c|c|c|c|c|c|c|}
\hline$\alpha$ & $S^{*}$ & $c$ & $R^{*}$ & $S 1$ & $S 2$ & $B$ & $T$ \\
\hline \multicolumn{8}{|c|}{ Case 1. $p=20, c_{2}=10, c_{s}=5, h=2, \pi=6$} \\
\hline \multirow[t]{3}{*}{1} & 65.9 & 5 & 20.8 & 29 & 58.3 & 214.2 & 301.5 \\
\hline & & $c^{*}=6.07$ & 15 & 32 & 74.3 & 195.2 & 301.5 \\
\hline & & 10 & 0 & 0 & 133.3 & 168.2 & 301.5 \\
\hline \multirow[t]{3}{*}{2} & 50.2 & 5 & 28.2 & 26.8 & 30.4 & 327.5 & 384.8 \\
\hline & & $c^{*}=7.79$ & 16.9 & 53.7 & 66.5 & 264.5 & 384.8 \\
\hline & & 10 & 0 & 0 & 144.6 & 240.2 & 384.8 \\
\hline \multirow[t]{3}{*}{3} & 43.7 & 5 & 29.7 & 21.4 & 19.7 & 367.8 & 408.9 \\
\hline & & $c^{*}=8.46$ & 18.5 & 67.7 & 58.2 & 282.9 & 408.9 \\
\hline & & 10 & 0 & 0 & 147 & 261.9 & 408.9 \\
\hline \multicolumn{8}{|c|}{ Case 2. $p=15, c_{2}=10, c_{s}=5, h=2, \pi=6$} \\
\hline \multirow[t]{3}{*}{1} & 56.1 & 5 & 20.8 & 29 & 51.9 & 83.7 & 164.6 \\
\hline & & $c^{*}=6.07$ & 15 & 32 & 67.9 & 64.8 & 164.6 \\
\hline & & 10 & 0 & 0 & 126.9 & 37.7 & 164.6 \\
\hline \multirow[t]{3}{*}{2} & 46.3 & 5 & 28.2 & 26.8 & 27.9 & 184.1 & 238.7 \\
\hline & & $c^{*}=7.79$ & 16.9 & 53.7 & 64.0 & 121.0 & 238.7 \\
\hline & & 10 & 0 & 0 & 142.0 & 96.7 & 238.7 \\
\hline \multirow[t]{3}{*}{3} & 41.4 & 5 & 29.7 & 21.4 & 18.2 & 221.4 & 261.1 \\
\hline & & $c^{*}=8.46$ & 18.5 & 67.7 & 56.8 & 136.6 & 261.1 \\
\hline & & 10 & 0 & 0 & 145.5 & 115.5 & 261.1 \\
\hline
\end{tabular}

In all cases, Supplier 1's maximum expected profit, $X^{*}$, occurred at $c^{*}=w_{2}>k$, so that it was never in his best interest to become the sole supplier for the buyer. Since the value of $R^{*}$ does not depend on $p$, changes in the selling price do not influence the maximum expected profit of Supplier 1 unless Supplier 1 finds it more profitable to set the value of $c$ below $k$, making him the sole supplier. On the other hand, Supplier 2's profit is sensitive to the changes in $p$. Ceteris paribus, the buyer's base stock level is positively related to $p$. Since Supplier 2's share of the buyer's total order amount is essentially a residual claim after Supplier 1, Supplier 2's expected profits change in the same direction as the change in the buyer's base stock level.

Table 3 also indicates that as $\alpha$ increases, supplier 1's expected profit per period, $c^{*} R^{*}-c_{\mathrm{s}} Q\left(R^{*}\right)$, also increases whereas the average order quantity from supplier 2, $Q_{2}$ decreases. These two outcomes cause the ratio of Supplier 1's profits to Supplier 2's profits to rise, indicating Supplier 1 gains more business from its market competitors under less variable demand. It can be said that this result is driven by the buyer's decreasing preference for a capacity reservation contract as the demand becomes less predictable.

\section{2. (SL, SU) policy results}

For the $(S L, S U)$ policy, we computed the optimal $c$ value for Supplier 1 and the corresponding optimal $R$ value for the buyer via numerical search. The search for $S L, S U$, and $R$ was conducted over the set of integer numbers by means of the discrete Hooke and Jeeves method as in Henig et al. (1997). To find $c^{*}$, we discretized the interval between $c_{s}$ and $c_{2}$ with 0.1 increments.

It is interesting to compare the resulting expected profits of the three parties in the system when Supplier 1 chooses an optimal $c$ value according to the type of the inventory policy used by the buyer. As shown in Tables 3 and 4, at $c^{*}$, the total profit in the system and the buyer's profit are relatively insensitive to the type of inventory policy used. On the other hand, going from a base stock policy to $(S L, S U)$ policy shifts a significant amount of revenue from Supplier 2 to Supplier 1. The optimal capacity price for Supplier 1 and the 
Table 4

Expected profits under $(S L, S U)$ policy

\begin{tabular}{|c|c|c|c|c|c|c|c|c|}
\hline$\alpha$ & $c^{*}$ & $R^{*}$ & $S L$ & $S U$ & $S 1$ & $S 2$ & $B$ & $T$ \\
\hline \multicolumn{9}{|c|}{ Case 1. $p=20, c_{2}=10, c_{s}=5, h=2, \pi=6$} \\
\hline 1 & 9.1 & 15 & 60 & 137 & 61.5 & 58.2 & 178.4 & 298.1 \\
\hline 2 & 9.3 & 19 & 48 & 99 & 81.7 & 49.5 & 251 & 382.2 \\
\hline 3 & 9.2 & 22 & 42 & 76 & 92.4 & 36.8 & 276.9 & 406.1 \\
\hline \multicolumn{9}{|c|}{ Case 2. $p=15, c_{2}=10, c_{s}=5, h=2, \pi=6$} \\
\hline 1 & 9.1 & 15 & 50 & 127 & 61.5 & 51.6 & 47.9 & 161.0 \\
\hline 2 & 9.1 & 20 & 44 & 98 & 82.0 & 42.2 & 111.5 & 235.7 \\
\hline 3 & 9.5 & 21 & 40 & 89 & 94.5 & 40.3 & 124.3 & 259.1 \\
\hline
\end{tabular}

buyer's capacity decision corresponding to that price also appear quite robust with regard to changes in the selling price. The selling price affects the buyer's profit significantly, but has little impact on Supplier 1's or Supplier 2's profits. This is not actually unexpected since $c_{2}$ is kept fixed in the model. It would be interesting to see if a similar pattern exists when the price charged by the shortterm supplier $c_{2}$ is also treated as a decision variable. Another interesting result is that, under the $(S L, S U)$ policy, $c^{*}$ changes only marginally across different demand distributions.

The $c^{*}$ for Supplier 1 is higher when the buyer implements an $(S L, S U)$ policy. For a given $c$ value, the buyer reserves a higher capacity under an $(S L, S U)$ policy compared to that under a base stock policy. In an $(S L, S U)$ policy the buyer generally holds higher levels of inventories which means, unlike the base stock policy, the unused portion of the reserved capacity is relatively smaller. This has a favorable impact on Supplier 1 since Supplier 1 can charge a high capacity price without experiencing a significant drop in the contract volume.

Our results indicate that $(S L, S U)$ policy is more desirable for Supplier 1. The buyer's expected profit is slightly higher under the base stock policy at $c^{*}$; for example, when $\alpha=2$ and $p=20$, the difference is $\$ 13.5(=264.5-251)$. Supplier 1's gain from the $(S L, S U)$ policy is $\$ 28(=81.7-$ 53.7) which is enough to cover the buyer's loss of $\$ 13.5$ if the buyer demands to be compensated. Of course, another way of enticing the buyer to an $(S L, S U)$ policy would be to offer a unit capacity price less than $c^{*}$. It is important to Supplier 1 that the buyer stays committed to implementing the inventory control policy based on which the contract was written. Otherwise, the buyer can first commit to a base stock policy to obtain a lower $c$ from Supplier 1, and later switch to an $(S L, S U)$ policy to earn windfall profits at the expense of Supplier 1.

Analogously to the base stock policy, we have observed that the value of the capacity reservation contract to the buyer under an $(S L, S U)$ policy decreases with increasing demand variability. Case 2 in Table 4 contains one representative example for this behavior (compare $D$ values for $\alpha=1$ and $\alpha=2$ ).

\subsection{Buyer-supplier coordination results}

Table 5 shows the corresponding $J_{\max }$ values for the examples of Table 3 . As shown in Table 5, the combined expected profit of the buyer and Supplier 1 increases when their decisions are coordinated. Although theoretically coordination yields benefits, from the buyer's perspective, it requires a

Table 5

Expected joint profit of the buyer and Supplier 1 under coordination

\begin{tabular}{llll}
\hline$p$ & $\alpha$ & $S$ & $J_{\max }=T$ \\
\hline 20 & 1 & 73.3 & 303.5 \\
& 2 & 52.9 & 385.5 \\
\multirow{2}{*}{15} & 3 & 45.2 & 409.3 \\
& 1 & 65.9 & 168.2 \\
& 2 & 50.2 & 240.2 \\
& 3 & 43.7 & 261.9 \\
\hline
\end{tabular}


higher level of commitment and dependence on a single source. As numerical examples illustrate, the optimal reserved capacity increases substantially by going from the buyer-Supplier 1-Supplier 2 triad to the buyer-Supplier 1 exclusive partnership.

\subsection{Base stock policy with two-part pricing}

Table 4 contains Supplier 1's maximum expected profit under a capacity reservation contract with linear pricing and open market competition. It is also possible for Supplier 1 to extract the same amount of profits by changing the contract characteristics. For example, the contract may require that the buyer follows a base stock policy with predetermined reserved capacity $R^{\mathrm{P}}$. Treating the capacity reservation amount as a given parameter may be more realistic in some cases. Under a base stock policy, the buyer's and Supplier 1's combined profits, as a function of the reserved capacity $R$ and base stock level $S$, are

$E P+S 1=\left(c_{2}-c_{\mathrm{s}}\right) Q_{1}(R)+\left(p-c_{2}\right) Q_{1}(S)-L(S)$.

For a certain range of predetermined capacity volumes $R=R^{\mathrm{P}}$, it is possible to find an implied base stock level $S=S_{i}$ that will make $E P+S 1$ in (11) equal to $B+S 1$ values tabulated in Table 5 .

As an example, suppose $R^{\mathrm{P}}=25$. Table 6 lists the resulting $S_{i}, S 2$, and $T$ values when we replicate the buyer's and Supplier 1's profits given in Table 4 by using a base stock policy.

There is a simple mechanism that will effectively distribute an average profit of $\$ S 1$ per period to

Table 6

Base stock level and Supplier 2's profit implied by prespecified capacity volume and buyer-Supplier 1 profits

\begin{tabular}{llllll}
\hline$p$ & $\alpha$ & $E P+S 1$ & $S_{i}$ & $S 2$ & $T$ \\
\hline \multirow{2}{*}{20} & 1 & 239.9 & 88.2 & 57.3 & 297.2 \\
& 2 & 332.7 & 64.5 & 43.4 & 376.1 \\
& 3 & 369.3 & 50.9 & 35.9 & 405.2 \\
15 & 1 & 109.4 & 78.4 & 54.2 & 163.6 \\
& 2 & 193.5 & 58 & 42.1 & 235.6 \\
& 3 & 218.8 & 51.6 & 36.0 & 254.8 \\
\hline
\end{tabular}

Supplier 1. Supplier 1 supplies the product at unit $\operatorname{cost} c_{\mathrm{s}}$, and the buyer pays Supplier 1 each period an additional fixed payment of $\$ S 1$. This type of contractual arrangement is known as a two-part tariff policy in the literature (Weng, 1997). Thus, for the buyer and Supplier 1, a base stock policy with two-part pricing yield profits equivalent to an $(S L, S U)$ policy under market equilibrium and linearly priced capacity. This equivalency between the two different contract schemes may be useful from a practical standpoint because of the simpler nature of the base stock policy.

\section{Conclusion}

We have studied the use of a capacity reservation contract as a vehicle for establishing a stronger connection in buyer-supplier relationships. A capacity reservation contract leads to a tighter interaction between a buyer and a supplier because it elevates the status of the supplier to a long term business partner from being one of many interchangeable suppliers in the open market. The inclusion of market suppliers in the model forces the two sides of the capacity reservation agreement to evaluate the viability of the agreement under competitive pressures. We find that an exclusive partnership between the buyer and preferred supplier necessitates a significantly higher capacity to be reserved compared to the option of dual sourcing. We have shown that it is possible to design a base stock inventory policy with a twopart pricing mechanism to match the two-number policy with linear pricing. Consequently, the buyer and the preferred supplier have more flexibility over selecting a suitable contract structure. Our computational results suggest that because it involves substantial increases in reservation capacity, single sourcing strategy may not be a practical alternative.

Long-term contracts allow a supplier to make more efficient production schedules and investment plans for the future (Treleven, 1987). Besides the reduced uncertainty in future revenues and operations, another benefit for the supplier will be the favorable treatment it may receive from the buyer by being the preferred supplier. For many 
industrial suppliers, this creates a first-mover advantage in becoming a supplier for products under development. Also, if there is learning by doing, the supplier's unit cost of production will decrease over time as a result of repeated orders, leading to a competitive advantage. Notwithstanding the benefits, it is also possible to argue that the responsibility of making a reserved capacity available involves some loss of flexibility, hence more costly resource allocations on the supplier side. From the buyer's perspective, establishment of a long-term relationship facilitates cooperating with the supplier in controlling and improving the quality of purchased items.

Various research extensions are possible. A game-theoretic analysis based on risk preferences and bargaining powers of the parties may yield further insight into the mechanism of negotiations between the buyer and the supplier. It is also possible to generalize our framework to the case when the buyer contracts with more than one longterm supplier; the solution in this case will depend on the order in which parties make their decisions. In addition to price-based competition among the suppliers, the differences between the quality and reliability of deliveries from the short- and longterm suppliers may be incorporated into the model. Finally, it may be interesting to investigate the problem of allocating a supplier's production capacity among multiple buyers within a capacity reservation framework.

\section{Acknowledgements}

The authors thank two anonymous referees for their helpful comments.

\section{Appendix A}

Proof of Proposition 1. We consider the family of random variables

$Y_{\theta}=\theta Y+(1-\theta) \mu, \quad 0 \leqslant \theta \leqslant 1$.

Recall that $\mu=E(Y) . \theta=1$ corresponds to the original random variable, $Y$. The higher the value of $\theta$, the more random the demand is. We use $R_{\theta}^{*}$ to denote the optimal reservation capacity when demand is $Y_{\theta}$. Similar notation applies to other quantities of interest under $Y_{\theta}$. Then we have

$F_{\theta}\left(R_{\theta}^{*}\right)=F\left(\left[R_{\theta}^{*}-(1-\theta) \mu\right] / \theta\right)=\left(c_{2}-c\right) / c_{2}$.

Hence,

$\left[R_{\theta}^{*}-(1-\theta) \mu\right] / \theta=R^{*}, \quad$ and

$R_{\theta}^{*}=\theta R^{*}+(1-\theta) \mu$.

Let $Q(r) \equiv Q_{1}(r)$. Recall that

$$
\begin{aligned}
Q(r) & =\int_{0}^{r} y f(y) \mathrm{d} y+r \int_{r}^{\infty} f(y) \mathrm{d} y \\
& =\mu-\int_{r}^{\infty}(y-r) f(y) \mathrm{d} y .
\end{aligned}
$$

Using Eqs. (3) and (5) in Gerchak and Mossman (1992), we obtain

$\int_{r_{\theta}}^{\infty}\left(y-r_{\theta}\right) f_{\theta}(y) \mathrm{d} y=\theta \int_{r}^{\infty}(y-r) f(y) \mathrm{d} y$.

Combining (A.2) and (A.3),

$$
\begin{aligned}
Q_{\theta}\left(R_{\theta}^{*}\right) & =\mu-\int_{r_{\theta}}^{\infty}\left(y-r_{\theta}\right) f_{\theta}(y) \mathrm{d} y \\
& =\theta Q\left(R^{*}\right)+(1-\theta) \mu .
\end{aligned}
$$

From Section 4.2 we have

$B 12-B 2=-c R^{*}+c_{2} Q\left(R^{*}\right)$

Substituting (A.1) and (A.4) in

$D_{\theta}=B 12_{\theta}-B 2_{\theta}=-c R_{\theta}^{*}+c_{2} Q_{\theta}\left(R_{\theta}^{*}\right)$,

and using (A.5) we obtain

$D_{\theta}=\left(c_{2}-c\right)(1-\theta) \mu+\theta(B 12-B 2)$.

Using (A.5), and the inequalities

$\mu>Q\left(R^{*}\right), \quad$ and $\quad R^{*}>Q\left(R^{*}\right)$,

we have

$\left(c_{2}-c\right) \mu>\left(c_{2}-c\right) Q\left(R^{*}\right)>B 12-B 2$.

Finally, (A.6) and (A.7) imply that

$\mathrm{d} D_{\theta} / \mathrm{d} \theta<0, \quad 0 \leqslant \theta \leqslant 1$. 
According to (A.8), while keeping the mean demand fixed, expected savings from a capacity reservation contract monotonically decreases as the demand uncertainty increases.

Proof of Proposition 2. It can be shown that

$$
\begin{aligned}
& \mathrm{d} Q_{1}(r) / \mathrm{d} c=(\mathrm{d} r / \mathrm{d} c) F_{\mathrm{c}}(r), \\
& \mathrm{d} R^{*} / \mathrm{d} c=-\left[c_{2} f\left(R^{*}\right)\right]^{-1}, \\
& \mathrm{~d} R^{* *} / \mathrm{d} c=-\left[(p+\pi+h) f\left(R^{* *}\right)\right]^{-1}, \\
& \mathrm{~d} X_{1} / \mathrm{d} c=R^{* *}-\left[c\left(p+\pi+h-c_{\mathrm{s}}\right)-h c_{\mathrm{s}}\right] \\
& \quad \times(p+\pi+h)^{-2}\left[f\left(R^{* *}\right)\right]^{-1}, \\
& \mathrm{~d}^{2} X_{1} / \mathrm{d} c^{2}=\left\{(p+\pi+h) f\left(R^{* *}\right)\right\}^{-1} \\
& \quad \times\left\{-2-\left[c\left(p+\pi+h-c_{\mathrm{s}}\right)-h c_{\mathrm{s}}\right]\right. \\
& \quad \times\left[(p+\pi+h) f\left(R^{* *}\right)\right]^{-2}\left(\mathrm{~d} f\left(R^{* *}\right) / \mathrm{d} R^{* *}\right) \\
& \left.\quad+c_{\mathrm{s}}(p+\pi+h)^{-1}\right\}, \\
& \mathrm{d} X_{2} / \mathrm{d} c=R^{*}-c\left(c_{2}-c_{\mathrm{s}}\right) c_{2}^{-2}\left[f\left(R^{*}\right)\right]^{-1}, \\
& \mathrm{~d}^{2} X_{2} / \mathrm{d} c^{2}=\left\{1 /\left[c_{2} f\left(R^{*}\right)\right]\right\}\left\{-2-c\left(c_{2}-c_{\mathrm{s}}\right)\right. \\
& \left.\quad\left(\mathrm{d} f\left(R^{*}\right) / \mathrm{d} R^{*}\right) /\left[c_{2} f\left(R^{*}\right)\right]^{2}+c_{\mathrm{s}} / c_{2}\right\} .
\end{aligned}
$$

IFR distributions have the property that the failure rate, $r(y)$, increases as y increases (Leemis, 1995, p. 51), where

$r(y)=f(y) / F_{\mathrm{c}}(y)$.

Hence,

$\left.\mathrm{d} r(y) / \mathrm{d} y=\{[\mathrm{d} f(y) / \mathrm{d} y)] F_{\mathrm{c}}(y)+[f(y)]^{2}\right\} /\left[F_{\mathrm{c}}(y)\right]^{2}$.

In order to show the concavity of $X_{1}$, let

$$
\begin{aligned}
K_{1}= & \left\{-\left[\mathrm{d} f\left(R^{* *}\right) / \mathrm{d} R^{* *}\right] F_{\mathrm{c}}\left(R^{* *}\right)\right\} /\left[f\left(R^{* *}\right)\right]^{2}, \\
\varphi_{1}= & -2 h(p+\pi+h)+c_{\mathrm{s}} h+\left(K_{1}-2\right) c(p+\pi+h) \\
& +c_{\mathrm{s}} c-K_{1} c_{\mathrm{s}} c-K_{1} h c_{\mathrm{s}}, \\
\varphi_{2}= & -2 h(p+\pi+h)+c_{\mathrm{s}} h-2 c(p+\pi+h) \\
& +c_{\mathrm{s}} c+K_{1}\left[c(p+\pi+h)-c_{\mathrm{s}} c-h c_{\mathrm{s}}\right] .
\end{aligned}
$$

Note that $\varphi \equiv \varphi_{1}=\varphi_{2}$,

$$
\begin{aligned}
\mathrm{d}^{2} X_{1} / \mathrm{d} c^{2}=\varphi & \{(h+c) \\
& \left.\times(p+\pi+h)^{2} f\left(R^{* *}\right)\right\}^{-1} .
\end{aligned}
$$

If the distribution is IFR, (A.9) is positive, which implies $K_{1}<1 . X_{1}$ is concave since (A.10) is always negative if $K_{1}<1$ : this is because $\varphi=\varphi_{1}<0$ if $0 \leqslant K_{1}<1$, and $\varphi=\varphi_{2}<0$ if $K_{1}<0$. Similarly, let

$$
K_{2}=\left\{-\left[\mathrm{d} f\left(R^{*}\right) / \mathrm{d} R^{*}\right] F_{\mathrm{c}}\left(R^{*}\right)\right\} /\left[f\left(R^{*}\right)\right]^{2} .
$$

Then

$$
\begin{aligned}
\mathrm{d}^{2} X_{2} / \mathrm{d} c^{2}= & \left\{1 /\left[c_{2} f\left(R^{*}\right)\right]\right\} \\
& \times\left\{-2+K_{2}+c_{\mathrm{s}}\left(1-K_{2}\right) / c_{2}\right\} .
\end{aligned}
$$

IFR implies that $K_{2}<1$; (A.11) is always negative if $K_{2}<1$, hence, $X_{2}$ is concave for all IFR distributions.

Finding $w_{1}$ and $w_{2}$ when demand distribution is Weibull

For the Weibull distribution,

$$
\begin{aligned}
& F(y)=1-\exp \left[-(y / \beta)^{\alpha}\right], \\
& f(y)=\alpha \beta^{-\alpha} y^{\alpha-1} F_{\mathrm{c}}(y) .
\end{aligned}
$$

$\beta>0$ and $\alpha>0$ are the scale and shape parameters, respectively. Weibull is IFR if $\alpha \geqslant 1$. Using the relationship

$y=\beta \exp \left\{\alpha^{-1} \ln \left[-\ln F_{\mathrm{c}}(y)\right]\right\}$,

it can be shown that

$$
\begin{aligned}
& \left(w_{1}+h\right) /(p+\pi+h) \\
& \quad=\exp \left\{\left[h c_{\mathrm{s}}-w_{1}\left(p+\pi+h-c_{\mathrm{s}}\right)\right]\right. \\
& \left.\quad \times\left[\alpha\left(w_{1}+h\right)(p+\pi+h)\right]^{-1}\right\}, \\
& w_{2}=c_{2} \exp \left[\left(c_{\mathrm{s}}-c_{2}\right) /\left(\alpha c_{2}\right)\right] .
\end{aligned}
$$

Unlike the direct solution for $w_{2}$, a nonlinear equation must be solved to determine the unique $w_{1} . X_{i}\left(w_{i}\right)$ can be evaluated by observing that

$Q_{1}(r)=\mu-(\beta / \alpha) \Gamma(1 / \alpha)\left[1-I\left(1 / \alpha,(r / \beta)^{\alpha}\right)\right]$

for the Weibull distribution (Leemis, 1995, p. 89), where $\Gamma(s)$ is the gamma function, and $I(s, t)$ is the incomplete gamma function defined as follows: 


$$
\begin{aligned}
& \Gamma(s)=\int_{0}^{\infty} u^{s-1} \exp (-u) \mathrm{d} u \text { for } s>0, \\
& I(s, t)=[1 / \Gamma(s)] \int_{0}^{t} u^{s-1} \exp (-u) \mathrm{d} u \\
& \quad \text { for } s>0 \text { and } t>0 .
\end{aligned}
$$

There exist many mathematical software packages that can be used to compute $\Gamma(s)$ and $I(s, t)$.

\section{References}

Barnes-Schuster, D., Bassok., Y., Anupindi, R., 1998. Supply contracts with options: Flexibility, information, and coordination. Working Paper, University of Chicago.

Bassok, Y., Anupindi, R., 1997. Analysis of supply contracts with total minimum commitment. IIE Transactions 29, 373-381.

Bazaraa, M.S., Sherali, H.D., Shetty, C.M., 1993. Nonlinear Programming: Theory and Applications, second ed. Wiley, New York.

Brown, A.O., Lee, H.L., 1997. Optimal Pay to delay capacity reservation with application to the semiconductor industry. Working Paper, Stanford University.

Cohen, M.A., Agrawal, N., 1999. An analytical comparison of long- and short-term contracts. IIE Transactions 31, 783796.

De Toni, A., Nassimbeni, G., 1999. Buyer-supplier operational practices, sourcing policies and plant performances: Results of an empirical research. International Journal of Production Research 37, 567-619.

Eppen, G.D., Iyer, A.V., 1997. Backup agreements in fashion buying - the value of upstream flexibility. Management Science 43, 1469-1484.

Gerchak, Y., Mossman, D., 1992. On the effect of demand randomness on inventories and costs. Operations Research 40, 804-807.

Gibbons, R., 1992. Game Theory for Applied Economists. Princeton University Press, Princeton, NJ.

Helper, S.R., Sako, M., 1995. Supplier Relations in Japan and the United States: Are They Converging? Sloan Management Review, Spring, 77-84.
Henig, M., Gerchak, Y., Ernst, R., Pyke, D.F., 1997. An inventory model embedded in designing a supply contract. Management Science 43, 184-189.

Lee, H.L., Padmanabhan, V., Whang, S., 1997. Information distortion in a supply chain: The bullwhip effect. Management Science 43, 546-558.

Leemis, L.M., 1995. Reliability-Probabilistic Models and Statistical Methods. Prentice-Hall, Englewood Cliffs, NJ.

Li, C., Kouvelis, P., 1999. Flexible and risk-sharing supply contracts under price uncertainty. Management Science 45, 1378-1398.

Lyons, T.F., Krachenberg, A.R., Henke, J.W., 1990. Mixed motive marriages: What's next for buyer-supplier relations? Sloan Management Review, Spring, 29-36.

Maloni, M.J., Benton, W.C., 1997. Supply chain partnerships: Opportunities for operations research. European Journal of Operational Research 101, 419-429.

Nahmias, S., 1993. Production and Operations Analysis, second ed. Irwin, Homewood, IL.

Porteus, E.L., 1990. Stochastic Inventory Theory. In: Heyman, D.P., Sobel, M. (Eds.), Handbooks in OR \& MS. vol. 2, Stochastic Models. North-Holland, New York.

Seshadri, S., Chatterjee, K., Lilien, G.L., 1991. Multiple source procurement competitions. Marketing Science 10, 246263.

Subramaniam, V., 1998. Efficient sourcing and debt financing in imperfect product markets. Management Science 44, 1167 1178.

Thomas, D.J., Griffin, P.M., 1996. Coordinated supply chain management. European Journal of Operational Research 94, 1-15.

Treleven, M., 1987. Single sourcing: A management tool for the quality supplier. Journal of Purchasing and Materials Management, Spring 1987, 19-24.

Tsay, A.A., Nahmias, S., Agrawal, N., 1999. Modeling supply chain contracts: A review. In: Tayur, S., Ganeshan, R., Magazine, M. (Eds.), Quantitative Models for Supply Chain Management. Kluwer Academic Publishers, Norwell, MA.

Weng, Z.K., 1997. Pricing and ordering strategies in manufacturing and distribution alliances. IIE Transactions 29, 681692.

Williamson, O.E., 1991. Comparative economic organization: The analysis of discrete structural alternatives. Administrative Science Quarterly 36, 269-296. 